\title{
El sincrotró ALBA, una eina de futur
}

\author{
Carla Prat Llenas $\bowtie$ \\ Alumna de l'Institut Llobregat, Sallent
}

Els sincrotrons, com l'ALBA, són un tipus d'accelerador de partícules que tenen un gran nombre d'aplicacions en gran diversitat de camps. Són també una de les inversions actualment més importants en el món de la física ja que permeten -i seguiran permetent en un futur proper- mostrar a l'ésser humà tot allò que el seu ull no és capaç de veure.

Paraules clau: sincrotró, radiació sincrotró, camp elèctric, camp magnètic, electró

\section{Introducció}

Aquest article és fruit de la realització d'un Treball de Recerca de Batxillerat que porta com a títol "El sincrotró ALBA. Objectiu: Cristal-lografia macromolecular". L'objectiu del treball és conèixer i comprendre el funcionament d'un sincrotró i aplicar aquest coneixement a una línia d'investigació real de l'ALBA anomenada Cristal-lografia macromolecular, coneguda també amb el nom de XALOC.

Per al seu bon funcionament, aquesta línia requereix unes característiques molt concretes de radiació sincrotró; és per això que el projecte pretén dur a terme els càlculs per conèixer un seguit de paràmetres físics dels electrons i de la radiació que, més endavant, permetran l'obtenció de bons resultats a la línia d'investigació XALOC. En aquest article s'explica què es un sincrotró, tot comparantlo amb altres acceleradors, i quin és el seu funcionament. Igualment es dóna a conèixer la importància de la radiació sincrotró, llum que permet la realització de tots els experiments.

\section{Què és un sincrotró?}

Els acceleradors de partícules són, des de fa uns anys, els aparells destinats a la investigació per excel-lència. Gràcies a la seva complexitat a nivell estructural i tecnològic el nombre d'aplicacions que tenen resulta enorme. D'acceleradors en trobem de diferents tipus, sent cada un la millora de l'anterior. És d'aquesta manera que s'ha arribat al perfeccionat sincrotró.

Existeixen diferents mètodes d'acceleració que ens permeten dividir-los en dos grans grups. L'acceleració lineal la trobem representada pel LINAC o accelerador lineal que utilitza camps elèctrics i cavitats de radiofreqüència per accelerar les partícules. D'acceleradors circulars, que utilitzen camps magnètics per corbar la trajectòria de les partícules, en trobem de tres tipus diferents (taula 1 ).

\begin{tabular}{cccc} 
Màquina & $\begin{array}{c}\text { Freqüència } \\
(\mathrm{f})\end{array}$ & $\begin{array}{c}\text { Camp } \\
\text { magnètic } \\
(\mathrm{B})\end{array}$ & $\begin{array}{c}\text { Radi } \\
(\mathrm{r})\end{array}$ \\
Ciclotró & Constant & Constant & $\begin{array}{c}\text { Augmenta } \\
\text { amb l'energia }\end{array}$ \\
\hline $\begin{array}{c}\text { Sincro- } \\
\text { ciclotró }\end{array}$ & Variable & Constant & $\begin{array}{c}\text { Augmenta } \\
\text { amb l'energia }\end{array}$ \\
\hline Sincrotró & Variable & Variable & Constant
\end{tabular}

Taula 1. Resum esquemàtic dels tres tipus d'acceleradors circulars i les seves principals diferències.

El sincrotró resulta ser una millora dels acceleradors anteriors, ja que a diferència dels dos altres models, el camp magnètic i el camp elèctric estan sorprenentment sincronitzats, fet que es tradueix en un gran nombre d'avantatges; per això és el que actualment s'utilitza en les investigacions. 
Podem diferenciar entre dos tipus de sincrotrons. El primer, conegut com a Col-lisionador -de l'anglès collider- fa fer circular dos feixos de partícules en sentit contrari per fer-los xocar i poder estudiar el que resulta d'aquest energètic xoc; un bon exemple n'és el conegut LHC situat al CERN, a Ginebra. El segon, en canvi, acumula les partícules i les manté circulant durant llargs períodes de temps i és per això que se'l coneix com a Anell d'emmagatzematge o Storage ring. El sincrotró ALBA és l'exemple més proper que tenim d'aquest tipus de sincrotró.

\section{Quin és el seu funcionament?}

A l'ALBA les partícules carregades que circulen al llarg dels seus tubs de buit són els electrons. Per aconseguir que els electrons formin un corrent estable han de ser prèviament accelerats fins a assolir la seva energia final. Aquest procés se sol fer en dues etapes (fig. 1): la primera mitjançant un LINAC (accelerador lineal) que proporciona als electrons al voltant d'un $10 \%$ de la seva energia total; i en la segona etapa s'utilitza un accelerador circular que permet assolir l'energia final d'injecció. Un potent camp elèctric variable és el que s'encarrega d'accelerar les partícules mentre que per desviarles s'utilitza un camp magnètic situat perpendicularment al pla de la trajectòria. El camp magnètic no només s'encarrega de corbar el feix de partícules mitjançant imants dipolars sinó també de focalitzar-lo mitjançant imants quadrupolars i sextupolars. Cal tenir en compte que el camp magnètic no altera mai l'energia d'una partícula; és per això que al llarg de l'anell d'emmagatzematge hi trobem uns trams rectes on s'hi situen les cavitats de radiofreqüència que proporcionen al feix de partícules l'energia que ha perdut per radiació a cada desviació.

\section{La radiació sincrotró}

Quan el feix de partícules carregades és corbat per l'acció d'un camp magnètic pateix una acceleració centrípeta emetent una llum de propietats extraordinàries: la radiació sincrotró, descoberta casualment l'any 1947. En un sincrotró com l'ALBA és aquesta radiació la que s'utilitza per a tots els experiments i, per tant, és essencial. En canvi, en un sincrotró com I'LHC aquesta llum resulta ser una pèrdua d'energia i s'intenta evitar al màxim.

Per poder dur a terme experiments com els que es fan a l'ALBA calen unes característiques molt concretes de la llum, característiques que la radia- ció sincrotró ens ofereix en tota regla. En primer lloc cal dir que el seu rang espectral és immens $i$ que va des de l'infraroig fins als raigs $X$ més energètics; no existeix cap font de llum convencional que cobreixi un espectre tan ampli. Una de les seves propietats úniques és la seva alta intensitat, anomenada també brillantor, que permet realitzar experiments en temps molt petits i amb una alta resolució d'energia. Això permet observar processos en temps real, com per exemple qualsevol tipus de transformació estructural.

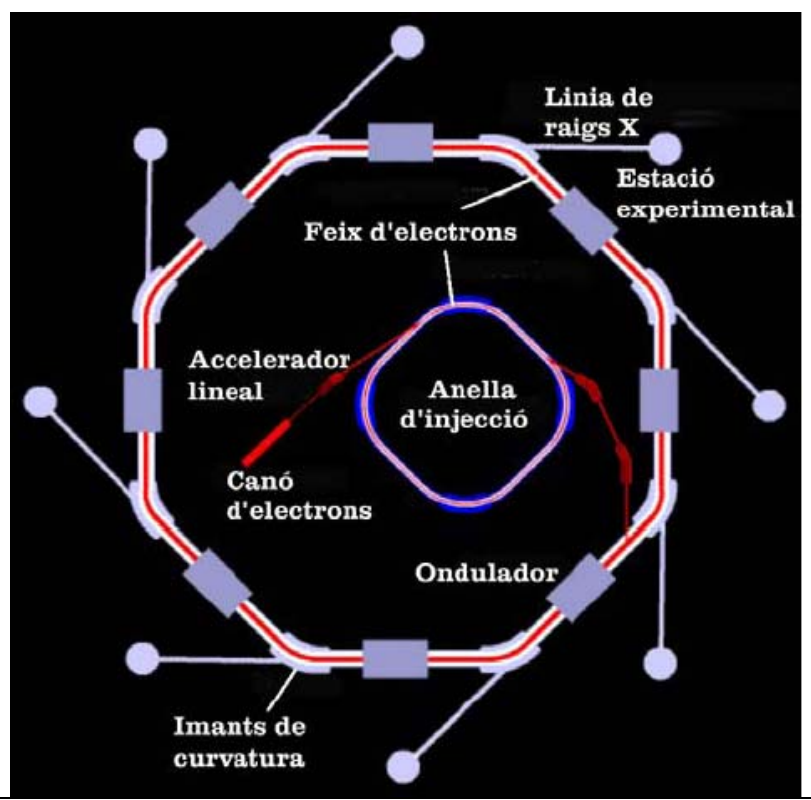

Figura 1. Esquema típic d'un sincrotró on es poden veure les diferents etapes d'acceleració. Font: Tesi d'Aseem Sharma.

Una de les característiques que diferencia els sincrotrons de tercera generació, com l'ALBA, de la resta són els anomenats dispositius d'inserció, que són imants multipolars que produeixen un moviment ondulant molt petit del feix d'electrons que fa que emeti llum en cada un dels trams corbats. El resultat és un feix extremadament brillant. Aquests tipus de dispositius, coneguts com onduladors, han permès un augment de fins a cinc ordres de magnitud en la brillantor respecte als de segona generació, basats exclusivament en imants de curvatura.

Una altra característica important a destacar de la radiació sincrotró és que està polaritzada. Aquest fet permet obtenir informació estructural i magnètica de la mostra que s'està estudiant.

Dues altres característiques que també són pròpies de la llum sincrotró són la coherència i l'estructura temporal del feix d'electrons. Els onduladors són els dispositius que permeten l'obtenció de 
radiació coherent. Pel què fa a l'estructura temporal del feix cal dir que està format per "paquets" separats per una certa distància (fig. 2).
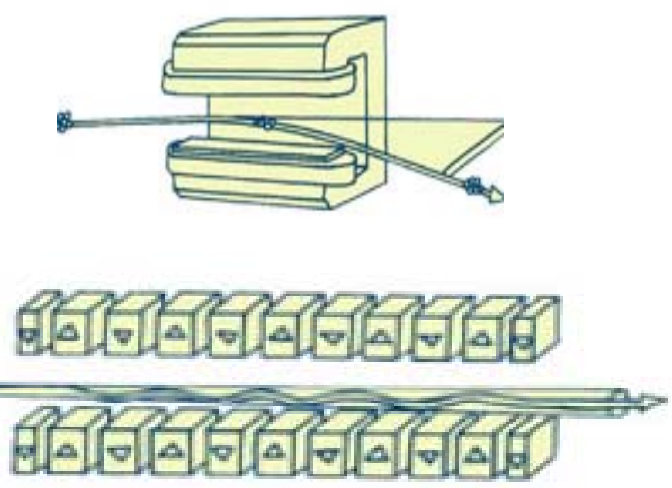

Figura 2. Comparació dels feix de llum produït per un imant de curvatura i per un ondulador.

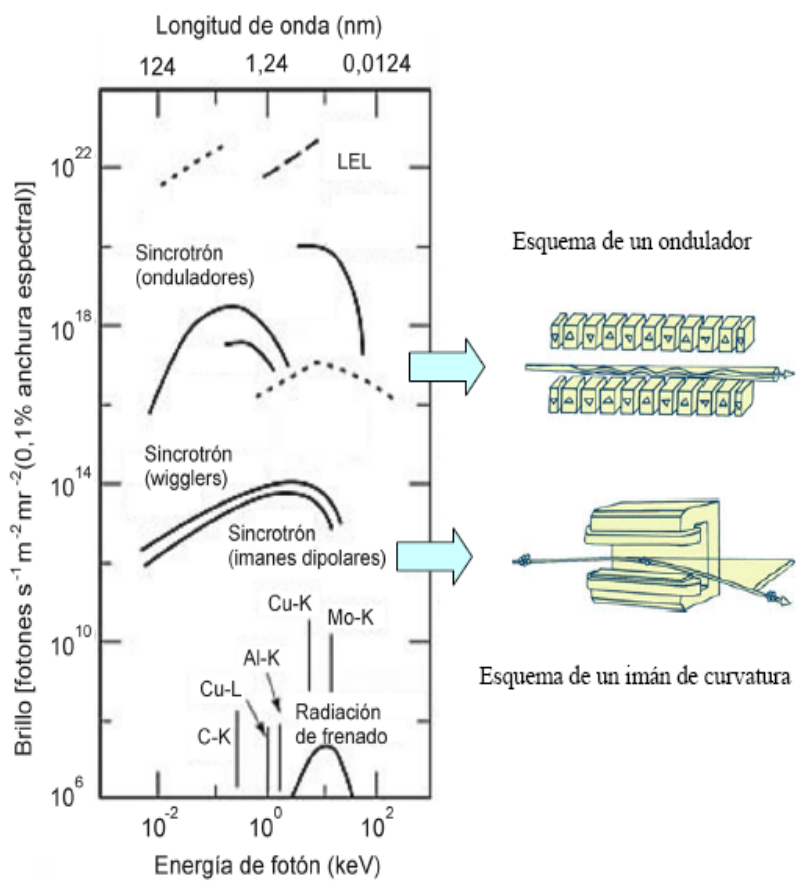

Figura 3. Densitat de fotons expressada mitjançant la brillantor en funció de l'energia; s'hi pot apreciar la diferència entre els imants de curvatura i els onduladors. Per sobre dels onduladors només hi ha els LEL, làsers d'electrons lliures. Font: Gutiérrez i al. (2004).

Els períodes que separen un pols de l'altre són de l'ordre de nanosegons; al sincrotró ALBA, concretament, es treballa amb un període de 2 ns. Aquesta característica és de gran utilitat per exemple, a l'hora de fer experiments en els quals s'excita algun procés intern d'una mostra mitjançant un pols de llum i s'estudia la seva reacció durant l'interval de temps que queda fins al pols següent.

D'aquesta manera la radiació, que en els seus inicis es creia que era una pèrdua, esdevé la base per qualsevol experiment que es realitzi al sincrotró.

Malgrat tot, els sincrotrons no són màquines perfectes i també tenen els seus desavantatges i inconvenients. Per començar cal trobar un lloc que compleixi les condicions que una estructura d'aquestes dimensions demana, on l'estabilitat és primordial. Juntament amb això apareix el problema de l'espai; malgrat que el sincrotró hagi permès solucionar el problema de les extremes dimensions dels antics acceleradors no deixa de ser una màquina gegant. Òbviament, i degut a la seva complexitat, el seu cost resulta ser molt elevat. Personalment, però, penso que realment val la pena invertir en instal-lacions tecnològicament avançades com aquesta ja que les seves aplicacions no només es queden en el camp de la física de partícules, sinó que agafen un ampli ventall amb moltes aplicacions que ajuden a la millora de la nostra qualitat de vida.

\section{Conclusions}

En aquests últims anys els sincrotrons han esdevingut un eina molt eficaç per a la recerca. Aquestes màquines, capaces de sincronitzar a la perfecció el camp elèctric amb el camp magnètic, han permès que mitjançant l'acceleració d'electrons es produeixi una llum, la radiació sincrotró, de propietats excepcionals i molt útil a la pràctica, esdevenint fonamental per a poder descobrir tot allò que fins avui ha restat ocult al nostre ull humà.

\section{Agraïments}

Dono les més sinceres gràcies a les dues persones que han fet possible la realització d'aquest Treball de Recerca: al meu tutor Josep Olivella per haver-me guiat i acompanyat des del començament i a la Dra. Montse Pont del sincrotró ALBA, perquè sense ella el treball no hagués estat possible i per tota la paciència i atenció que m'ha mostrat al llarg dels mesos que va durar la realització del treball.

\section{Bibliografia}

GUTIÉRREZ, Maite (2010). Y se hizo la luz. La Vanguardia. 22-3-2010 pag. 26 - pag. 27 
GUTIÉRREZ, Alejandro; MARTíN-GAGO, J. Ángel; FERRER, Salvador. (2004). La luz sincrotrón: una herramienta extraordinaria para la ciencia. Apuntes de Ciencia y Tecnología. Número 12, pág. 37 - pag. 45
WALKER, R.P, (1994). Synchrotron radiation. Cern Accelerator School. Número 26.

FALONE, Antonio (2010). Linears Accelerators. AL$B A$ [Data de consulta: Desembre 2010] web 